\title{
AN EMPIRICAL ANALYSIS OF THE ASSOCIATION BETWEEN NEIGHBORHOOD INCOME AND UNIT NON-RESPONSE IN THE SURVEY OF HEALTH, AGEING, AND RETIREMENT IN EUROPE
}

\author{
By AdriaAn KalwiJ* \\ Utrecht University and Network for Studies on Pensions, Aging and Retirement
}

\begin{abstract}
This paper estimates associations between individual and neighborhood characteristics and unit nonresponse in a survey of the population aged 50 and over in the Netherlands in 2004. The statistical model includes interviewer fixed effects to control for the non-random distribution of addresses over interviewers. The empirical analysis shows that, relative to individuals living in apartments, there is a lower unit non-response among individuals living in houses and a higher unit non-response among individuals living in old age institutions. Unit non-response is positively associated with the size of a city. No age and gender effects are found. Unit non-response is about 25 percent lower among individuals in the top than among individuals in the bottom of the distribution of neighborhood average income. This latter result implies that the response sample is biased toward individuals living in the more wealthy neighborhoods.
\end{abstract}

\section{INTRODUCTION}

Unit non-response rates in interview surveys with voluntary participation vary between 20 and 50 percent across western countries and are increasing over time (De Heer, 1999; De Leeuw and De Heer, 2002). High unit non-response rates constitute a major threat to the quality of data and are therefore a concern for empirical research. More specifically, when survey unit non-response is correlated with the variables of interest, this yields a selective response sample and statistical inferences concerning the target population may be biased. ${ }^{1}$ Despite the importance of unit non-response, its determinants have been given very little attention in empirical economic research. The main reason for this is that usually one has no information on the unit non-respondents.

This paper aims to contribute to the empirical literature on survey unit non-response by examining how unit non-response varies with individual and neighborhood characteristics. Of particular interest is the relationship between neighborhood average individual income and unit non-response, since in empirical socioeconomic research the variable of interest is often income or a variable that is

Note: I wish to thank Rob Alessie, Hans Bloemen, Arthur van Soest, two anonymous referees, and the seminar participants at the Utrecht School of Economics and a workshop organized by the Network for Studies on Pensions, Ageing and Retirement (NETSPAR) for helpful comments and suggestions. I am very grateful to Karin Bodewes, Matthijs de Gier, and Ralph de Jong from the survey agency TNS-NIPO, the Netherlands, for providing valuable insights in the fieldwork of the survey. Financial support has been provided by Stichting Instituut GAK through NETSPAR and the European Community's 5th framework program (QLK6-CT-2002-002426, QLK6-CT-2001-00360).

*Correspondence to: Adriaan Kalwij, Utrecht University, Utrecht School of Economics, Janskerkhof 12, 3512 BL Utrecht, the Netherlands (a.s.kalwij@uu.nl).

${ }^{1} \mathrm{~A}$ weighting scheme can to some extent correct for a selective response sample (Copas and Farewell, 1998; Little and Vartivarian, 2003). by Blackwell Publishing, 9600 Garsington Road, Oxford OX4 2DQ, UK and 350 Main St, Malden, MA, 02148, USA. 
correlated with income such as educational attainment, financial wealth, or homeownership. The data are drawn from the 2004 Survey of Health, Ageing and Retirement in Europe (SHARE, Börsch-Supan et al., 2005). This survey is held in 11 European countries among the population aged 50 and over. To estimate the associations between individual and neighborhood characteristics and unit nonresponse I use sampling frame data from the SHARE survey held in the Netherlands. In the Netherlands the survey has a 44 percent unit non-response rate, which is around the European average (De Luca and Peracchi, 2005). The sampling frame data contain information on individuals who cooperated and participated in the survey (the respondents) as well as on individuals who refused to cooperate and did not participate in the survey (the non-respondents). Apart from several individual characteristics (age, gender, and type of accommodation), the sampling frame data contains information on which interviewer contacted the individual and the postcode area where the individual lives. This latter information is used to supplement the sampling frame data with data from Statistics Netherlands on the neighborhood's population density and average individual income. Furthermore, the empirical model controls for the non-random distribution of addresses over interviewers by including interviewer fixed effects. The results from this paper provide insights into the validity of the assumption commonly made in empirical socioeconomic research that survey unit non-response is random (with respect to the variables of interest) and the direction of the potential non-response bias when using SHARE data from the Netherlands.

Groves and Couper (1998) discuss theoretical grounds for expecting unit non-response to be correlated with socioeconomic status variables such as educational attainment and income. The explanations they discuss are that reciprocal behavior may depend on socioeconomic status and that the opportunity cost of participation may depend on income. The empirical evidence on the relationship between unit non-response and socioeconomic variables is rather mixed. For instance, Groves and Couper (1998), using U.S. data, show that people of lower socioeconomic status or individuals living in neighborhoods with relatively low median housing value are more likely to participate, while Goyder et al. (2002), using Canadian data, show that people of higher socioeconomic status are more likely to participate. Khare et al. (1994), using the U.S. National Health and Nutrition Examination Survey III, report a negative correlation, and Korinek et al. (2006), using state-level data from the U.S. Current Population Survey, report a positive correlation between unit non-response and income. Apart from individual characteristics, the interviewers' characteristics also play an important role for gaining cooperation. Empirical studies report considerable differences in unit non-response rates of interviewers (O’Muircheartaigh and Campanelli, 1999; Snijkers et al., 1999; Groves and McGonagle, 2001; Pickery and Loosveldt, 2002). Groves and Couper (1998) provide some explanations for the presence of interviewer effects. For instance, they find that interviewers who are self-confident have lower refusal rates and, once controlled for this, interview experience plays no significant role. Kennickell (1999), using the 1995 U.S. Survey of Consumer Finances, reports that interviewers having experience with computers or who think of themselves a little as actors are significantly less likely to have refusals. Groves and McGonagle (2001) report that training interviewers in recruiting sample 
individuals to be respondents increases cooperation rates. Excellent overviews of the literature and further discussions on possible causes of unit non-response can be found in Groves and Couper (1998) and Stoop (2005).

The outline of this paper is as follows. Section 2 discusses the sample design and the data. Section 3 describes the statistical framework for analyzing unit non-response. Section 4 presents the empirical results and Section 5 concludes.

\section{Sample Design, Fieldwork, and the Data}

The 2004 Survey of Health, Ageing and Retirement in Europe (SHARE, www.share-project.org) is designed after the U.S. Health and Retirement Study (Juster and Suzman, 1995) and the English Longitudinal Study of Ageing (Marmot et al., 2003). SHARE is a survey on the life circumstances of over 22,000 individuals aged 50 and over in 11 European countries. The survey asks questions concerning their health, family, social network, and economic situation. I only have sampling frame data for the Netherlands, i.e. data on both the respondents and non-respondents, and therefore I restrict the analysis to the Netherlands. The target population is equal to 5.2 million individuals, which is about 32 percent of the total population in the Netherlands in 2004. This target population includes individuals living in old age institutions such as nursing homes. The survey was conducted between May 1 and mid-December 2004.

\subsection{Sample Design and Fieldwork}

The Dutch sampling frame is based on the population registers of the municipalities and has a two-stage self-weighted design. In the first stage, 20 municipalities are drawn from the total of 489 municipalities. In the second stage, 3546 target individuals were randomly selected from the population aged 50 and over in the municipalities selected in the first stage. ${ }^{2}$

A detailed description of the fieldwork of SHARE can be found in De Luca and Lipps (2005). Below I describe the, for this paper, most relevant aspects of the fieldwork of SHARE in the Netherlands. The survey agency distributed the names and addresses of the target individuals to 70 interviewers. The interviewers were explicitly instructed not to make contact by telephone, were also not provided with telephone numbers, and had to contact the target individuals in person, i.e. a face-to-face screening process. The target individuals received an advance letter stressing the importance of the survey and containing notice that an interviewer would contact him or her in person within one or two weeks. The interviewers did not receive all the addresses at once but every few weeks were given a list of new addresses to which, at the same time, the advance letters were sent. With the letter, the individuals also received a brochure describing the purpose of the survey. Some interviewers work faster than others and these often handled more cases. Furthermore, an interviewer was usually given addresses closest to his or her home.

\footnotetext{
${ }^{2}$ The selection probability of a municipality is equal to a municipality's population aged 50 and over divided by the target population. Several months before the start of the survey, 177 individuals were randomly selected in 14 municipalities, and 178 individuals were randomly selected in 6 municipalities.
} 
Unfortunately this allocation procedure implies that addresses are not assigned to interviewers completely at random. I return to this issue in Sections 3 and 4.

Contact failure is often a source of unit non-response (Groves and Couper, 1998), but in this survey, in the Netherlands, the interviewers experienced no problems in contacting the individuals. Conditional on valid addresses and the individuals being alive, no contact failures have occurred. In this respect the Netherlands is doing remarkably well compared to the other countries participating in SHARE (De Luca and Peracchi, 2005). Most contacts had been established within several days or at most, in case of holidays, a few weeks after the advance letter and brochure were sent and the address was allocated to the interviewer. The contact always needed to be established with the selected individual and not with a family member or neighbor. For contacting an individual living in an old age institution, such as a nursing home, the interviewer first had to contact the administration of the institution and request permission to contact the target individual. This permission was always granted.

All individuals were contacted face-to-face. When contacted, it could be established whether or not the individual was willing to participate in the survey. I refer to the willingness to participate in the survey as cooperation. If an individual was not capable of participating, for instance because of health limitations, a family member or close friend could respond on his or her behalf. But also in this case the target individual must be the one who decides whether or not to cooperate and consent to such a proxy interview. In the case of cooperation, interviews were scheduled with the individual and possibly other household members such as the spouse. The financial incentive for the target individual to cooperate was a $€ 15$ gift voucher, irrespective of the number of household members that were interviewed. In 25 cases the individual was deceased and in 13 cases the address was invalid and no new valid address was obtained. Following the AAPOR (2000) guidelines, these are labeled as non-sample cases. In 24 cases, sampling frame data was missing. For the remaining 3484 individuals all sampling frame data are available.

\subsection{Unit (Non)-Response and a Refusal Conversion Procedure}

SHARE implemented a refusal conversion procedure for the Netherlands to reduce unit non-response (De Luca and Lipps, 2005). This procedure is essentially a second attempt for cooperation of the target individual. This second, and final, attempt was made some time, at most two months, after the individual refused to cooperate at the first contact.

A consequence of using a refusal conversion procedure of importance to the empirical analysis below is that there are two routes leading to unit non-response. At the first contact, the individual was asked whether or not he or she was willing to cooperate. The outcome could be: (i) refusal; (ii) soft refusal; or (iii) cooperation. Individuals who made it very clear they did not wish to cooperate were labeled "refusals," sometimes referred to as "hard refusals," and individuals who, for example, hesitated or indicated it was not a convenient time were labeled "soft refusals." For instance, the most common reason given for not cooperating was "no time"; in such a situation the individual was labeled a soft refusal. The distinction between a refusal and a soft refusal depends on the interviewer's 
assessment of the reason for not cooperating. The survey manager took the decision whether or not to label a case as a soft refusal based on the reason for not cooperating that was provided by the interviewer. Although all interviewers have been given the same instructions, the interviewers' assessments can be influenced by their own interpretation of the situation. For instance, "not interested" can be interpreted either as not being interested at the time of contact, hence may be interested at a later time and labeled a soft refusal, or as not being interested in participating in surveys ever, given a code reflecting a reluctance to participate, and labeled a hard refusal.

The second cooperation attempt is referred to as the refusal conversion procedure. Before being contacted a second time, the individuals labeled as soft refusals again received the brochure and an advance letter in which cooperation was requested. They were not given any additional incentive to cooperate and interviewers did not receive additional training in between the two cooperation attempts. No failures of making contact on the second visit have been reported. The outcome of the second contact could be: (i) refusal; or (ii) cooperation. The main difference between the first and second contact is that in most cases ( 79 percent) a different interviewer was sent to the address. The reason for doing this is that a change of interviewer may yield a better match between the target individual and the interviewer in terms of cooperativeness. The interviewer is most often substituted by one of the other interviewers operating in the same municipality.

\subsection{Unit (Non)-Response, Descriptive Statistics, and Postal Code Information}

Table 1 reports the unit response rates. The unit response rate of the survey is 56 percent, hence a 44 percent unit non-response rate. At the first contact, 50.2 percent of the target individuals cooperated and 28.6 percent were labeled soft refusals. At the second contact, 20 percent of the individuals labeled soft refusals at the first contact were willing to cooperate ( 5.8 percentage points); this represents a 12 percent increase in the unit response rate. The additional response of this refusal conversion procedure is lower than the 26 percent increase in the unit response rate reported by Loosveldt et al. (2004) for the Netherlands in the European Social Survey (ESS; http://www.europeansocialsurvey.org/). A reason for this may be the fact that the ESS contacted most initial refusals (soft and hard refusals) once more.

TABLE 1

Unit Response AND ReFusal CONVERSION

\begin{tabular}{lcr}
\hline \hline Unit Response & $\begin{array}{c}\text { Number of } \\
\text { Individuals }\end{array}$ & $\begin{array}{c}\% \text { of } \\
\text { Individuals }\end{array}$ \\
\hline Hard refusal & 738 & 21.2 \\
Soft refusal, not converted & 793 & 22.8 \\
Soft refusal, converted to cooperation & 202 & 5.8 \\
Interview/cooperation & 1,751 & 50.2 \\
Total number of individuals & 3,484 & 100.0 \\
\hline
\end{tabular}


Review of Income and Wealth, Series 56, Number 2, June 2010

TABLE 2

INDIVIDUAL, NEIGHBORHOOD, AND INTERVIEWER CHARACTERISTICS

\begin{tabular}{|c|c|c|c|}
\hline Variable & \multicolumn{3}{|c|}{$\%$ of Observations } \\
\hline $\begin{array}{l}\text { Gender } \\
\text { Female } \\
\text { Male }\end{array}$ & & $\begin{array}{l}53.3 \\
46.7\end{array}$ & \\
\hline $\begin{array}{l}\text { Age group (years) } \\
50-54 \\
55-59 \\
60-64 \\
65-69 \\
70-74 \\
75-79 \\
\geq 80\end{array}$ & & $\begin{array}{r}21.2 \\
19.5 \\
15.2 \\
12.9 \\
11.5 \\
8.5 \\
11.2\end{array}$ & \\
\hline $\begin{array}{l}\text { Type of accommodation } \\
\text { Old age institution (elderly or nursing home) } \\
\text { House } \\
\text { Apartment }\end{array}$ & & $\begin{array}{r}3.6 \\
64.3 \\
32.2\end{array}$ & \\
\hline $\begin{array}{l}\text { Size of the city } \\
\text { Less than } 100,000 \text { inhabitants } \\
100,000-200,000 \text { inhabitants } \\
\text { More than } 200,000 \text { inhabitants }\end{array}$ & & $\begin{array}{l}60.0 \\
24.9 \\
15.1\end{array}$ & \\
\hline $\begin{array}{l}\text { Month of contact } \\
\text { May } \\
\text { June } \\
\text { July } \\
\text { August } \\
\text { September } \\
\text { October } \\
\text { November or December }\end{array}$ & $\begin{array}{c}\text { First contact } \\
20.5 \\
29.2 \\
21.0 \\
14.0 \\
10.6 \\
3.8 \\
0.9\end{array}$ & & $\begin{array}{l}\text { ontact } \\
0 \\
0 \\
5 \\
8 \\
3 \\
7 \\
6\end{array}$ \\
\hline $\begin{array}{l}\text { Neighborhood information (postcode level) } \\
\text { Population density }{ }^{\mathrm{a}} \\
\text { Average individual income }^{\mathrm{b}}\end{array}$ & $\begin{array}{c}\text { Minimum } \\
14 \\
23,064\end{array}$ & $\begin{array}{r}\text { Mean } \\
5,094 \\
32,921\end{array}$ & $\begin{array}{l}\text { Maximum } \\
25,776 \\
55,100\end{array}$ \\
\hline $\begin{array}{l}\text { Interviewer characteristics } \\
\text { Age } \\
\text { Gender }(1=\text { male }) \\
\text { Unit response rate (in \%) }\end{array}$ & $\begin{array}{c}\text { Minimum } \\
22.0 \\
0.0 \\
7.4\end{array}$ & $\begin{array}{c}\text { Mean } \\
54.6 \\
0.4 \\
41.2\end{array}$ & $\begin{array}{c}\text { Maximum } \\
83.0 \\
1.0 \\
79.2\end{array}$ \\
\hline
\end{tabular}

Notes: ${ }^{a}$ Inhabitants per square kilometer at January 1, 1999. Source: Statistics Netherlands, 2000.

${ }^{\mathrm{b}}$ Average income per capita, in 1998 Dutch Guilders. Source: Statistics Netherlands, 2000.

The sampling frame data contain information on the respondents' gender, age, size of the city (municipality), and type of accommodation. The categories of accommodation are: old age institution (elderly or nursing home); house (detached, semi-detached, or terraced); and apartment. Table 2 reports on the sample means. Concerning the month of contact, Table 2 shows that most first contacts took place before October and that second contacts only took place after June. The bottom of Table 2 shows a very large difference between the minimum and maximum interviewer specific unit response rate.

Postcode area information is available from Statistics Netherlands (2000) on population density and average disposable individual income in $1998 .{ }^{3}$ The information available from Statistics Netherlands is on the four-digit level postcode

${ }^{3}$ This information is based on the population registry and tax records. 
(348 geographical areas). Kennickell (1999) also uses postcode area information for analyzing unit non-response, but has no information on average individual income within a postcode area. I refer to the postcode area as the "neighborhood." Table 2 shows that there is considerable variation within the sample in population density and average individual income in neighborhoods.

\section{A Unit (Non)-Response Model with One Refusal Conversion Attempt}

I use a latent variable model to estimate the associations between individual and neighborhood characteristics and unit (non)-response and the correlation between the two cooperation attempts. This model explicitly takes into account the two different routes leading to unit response that have been discussed above. The latent unit response variable is denoted by $R_{i t}^{*}$, where $i$ denotes the individual $(i=1, \ldots, N)$ and $t$ the contact time $(t=1,2)$. Hence, $t=1$ refers to the first cooperation attempt and $t=2$ refers to the second cooperation attempt. The latent response variable $R_{i t}^{*}$ is assumed to relate to a vector of covariates as follows:

$$
R_{i t}^{*}=\alpha+x_{i t} \beta+u_{i t}, \quad i=\{1, \ldots, N\}, t=\{1,2\} .
$$

The vector of covariates is denoted by $x_{i t}, \alpha$ is an intercept, and $\beta$ is a vector of parameters. The parameter vector $\beta$ provides insights into the associations between the observed covariates and unit (non)-response. The error term $u_{i t}$ includes unobserved characteristics. This error term is assumed to be normally distributed, $u_{i t} \sim N\left(0, \sigma_{u}^{2}\right)$, and independent of the explanatory variables. The error term is allowed to be correlated between the two cooperation attempts (at $t=1$ and $t=2$ ) and the corresponding correlation coefficient is denoted by $\rho$.

The observed covariates controlled for in the model are individual and neighborhood characteristics such as individual's age and gender, type of accommodation, and neighborhood's average individual income. These variables make it possible to assess to what extent unit non-response is correlated with socioeconomic status (Khare et al., 1994; Groves and Couper, 1998; Goyder et al., 2002). Khare et al. (1994) and Cohen and Duffy (2002) report that health status is positively correlated with unit response. To examine this issue I control, apart for age, for whether or not an individual is living in an old age institution such as a nursing home. In case of poor health (mental or physical) all individuals in the Netherlands have access to this type of health care. As discussed in Section 2, interviewers were in principle given addresses in the city closest to their homes; this implies that the distribution of addresses over the interviewers is non-random. A consequence of this is a possible unit non-response bias when there are differences between interviewers in the ability to convince a potential respondent to cooperate. For instance, if a relatively "good" interviewer is given addresses in a higher income neighborhood and a relatively "bad" interviewer is given addresses in a lower income neighborhood, then this allocation yields a spurious negative association between income and unit non-response. Empirical studies report considerable differences in unit non-response rates between interviewers (Kennickell, 1999; O’Muircheartaigh and Campanelli, 1999; Snijkers et al., 1999; Groves and 
McGonagle, 2001; Pickery and Loosveldt, 2002). Therefore I include in the final empirical specification interviewer fixed effects. This means that for each interviewer I include a dummy variable in the model. These dummy variables are allowed to change over time, since the interviewer who makes the first contact (at $t=1$ ) may differ from the interviewer who makes the second contact (at $t=2$ ). In the discussion of the results I refrain from interpreting the interviewer fixed effects because of the non-random distribution of addresses over the interviewers. For instance, an interviewer may have a low average response rate not because he or she is bad at gaining cooperation in general, but because the addresses assigned to this interviewer are in a neighborhood with a notoriously low response rate.

The latent variable in equation (1) is not observed and I only have information on a unit response indicator $R_{i t}$. The three possible outcomes at the first contact $(t=1)$ are (hard) refusal $\left(R_{i 1}=0\right)$, soft refusal $\left(R_{i 1}=1\right)$, and cooperation $\left(R_{i 1}=2\right)$. Only individuals who are labeled soft refusal $\left(R_{i 1}=1\right)$ are contacted a second time. As discussed above, I refer to the attempt to convert a soft refusal as the refusal conversion procedure. The two possible outcomes at the second contact $(t=2)$ are refusal $\left(R_{i 2}=0\right)$ and cooperation $\left(R_{i 2}=1\right)$. At the end of the survey period there are four possible unit response outcomes; these are assumed to relate to the latent response variable as follows:

$$
\begin{array}{llll}
\text { 1. } & R_{i 1}=0 & \text { if } & R_{i 1}^{*}<c_{1} \\
\text { 2. } & R_{i 1}=1, R_{i 2}=0 & \text { if } & c_{1} \leq R_{i 1}^{*}<c_{2}, R_{i 2}^{*}<c_{2} . \\
\text { 3. } & R_{i 1}=1, R_{i 2}=1 & \text { if } & c_{1} \leq R_{i 1}^{*}<c_{2}, R_{i 2}^{*} \geq c_{2} \\
\text { 4. } & R_{i 1}=2 & \text { if } & R_{i 1}^{*} \geq c_{2}
\end{array}
$$

The threshold parameters are introduced to make the distinction between the different possible outcomes. The outcome is a refusal at the first contact if the latent response is below threshold $c_{1}$. The outcome is a soft refusal if the latent response is above threshold $c_{1}$ and below threshold $c_{2}$. The outcome is cooperation if the latent response is above threshold $c_{2}$. At the second contact, a soft refusal is a (final) refusal since this is the last refusal conversion attempt. Equation (2) shows the two possible routes that lead to unit non-response (outcomes 1 and 2) and the two possible routes that lead to unit response (outcomes 3 and 4).

\subsection{Estimation and Identification}

Equations (1) and (2) form the unit response model that is estimated by Maximum Likelihood. The probability of a refusal at the first contact (outcome 1, equation (2)) is:

$$
\operatorname{Pr}\left[R_{i 1}^{*}<c_{1}\right]=\operatorname{Pr}\left[\alpha+x_{i 1} \beta+u_{i 1}<c_{1}\right] \equiv \Phi\left[\frac{c_{1}-\alpha}{\sigma_{u}}-x_{i 1} \frac{\beta}{\sigma_{u}}\right],
$$

where $\Phi($.$) denotes the standard normal distribution function. The probability of$ cooperation at the first contact (outcome 4, equation (2)) is: 


$$
\operatorname{Pr}\left[R_{i 1}^{*} \geq c_{2}\right]=\operatorname{Pr}\left[\alpha+x_{i 1} \beta+u_{i 1} \geq c_{2}\right] \equiv 1-\Phi\left[\frac{c_{2}-\alpha}{\sigma_{u}}-x_{i 1} \frac{\beta}{\sigma_{u}}\right]
$$

The probability of a soft refusal at the first contact and no cooperation at the second contact (outcome 2, equation (2)) is:

$$
\begin{aligned}
\operatorname{Pr} & {\left[c_{1}<R_{i 1}^{*} \leq c_{2}, R_{i 2}^{*}<c_{2}\right]=\operatorname{Pr}\left[R_{i 1}^{*} \leq c_{2}, R_{i 2}^{*}<c_{2}\right]-\operatorname{Pr}\left[R_{i 1}^{*}<c_{1}, R_{i 2}^{*}<c_{2}\right] } \\
= & \Phi^{2}\left[\frac{c_{2}-\alpha}{\sigma_{u}}-x_{i 1} \frac{\beta}{\sigma_{u}}, \frac{c_{2}-\alpha}{\sigma_{u}}-x_{i 2} \frac{\beta}{\sigma_{u}}, \rho\right] \\
& -\Phi^{2}\left[\frac{c_{1}-\alpha}{\sigma_{u}}-x_{i 1} \frac{\beta}{\sigma_{u}}, \frac{c_{2}-\alpha}{\sigma_{u}}-x_{i 2} \frac{\beta}{\sigma_{u}}, \rho\right],
\end{aligned}
$$

where $\Phi^{2}($.$) denotes the bivariate standard normal distribution function and \rho$ is the correlation coefficient. The probability of a soft refusal at the first contact and cooperation at the second contact (outcome 3, equation (2)) is:

$$
\begin{gathered}
\operatorname{Pr}\left[c_{1}<R_{i 1}^{*} \leq c_{2}, R_{i 2}^{*} \geq c_{2}\right]=1-\operatorname{Pr}\left[R_{i 1}^{*}<c_{1}\right]-\operatorname{Pr}\left[R_{i 1}^{*} \geq c_{2}\right]- \\
\operatorname{Pr}\left[c_{1}<R_{i 1}^{*} \leq c_{2}, R_{i 2}^{*}<c_{2}\right] .
\end{gathered}
$$

The threshold parameters $c_{1}$ and $c_{2}$ determine whether the response is a cooperation, soft refusal, or hard refusal. These two parameters are not separately identified from $\alpha$ (the intercept parameter). Furthermore, the resulting two constants and slope parameters $(\beta)$ are identified only up to a scale factor $\left(\sigma_{u}\right)$. The identifiable parameters of interest are denoted by: $\theta=\left(\frac{c_{1}-\alpha}{\sigma_{u}}, \frac{c_{2}-\alpha}{\sigma_{u}}, \frac{\beta}{\sigma_{u}}, \rho\right)$.

The standard deviation $\sigma_{u}$ can be normalized to 1 without affecting the results. The Maximum Likelihood estimates are given by:

$$
\hat{\theta}=\underset{\theta}{\arg \max } \sum_{i=1, \ldots, N} \ln \left(L_{i}\left(R_{i 1}, R_{i 2} \mid x_{i 1}, x_{i 2}, \theta\right)\right),
$$

with the likelihood function

$$
\begin{aligned}
& L_{i}\left(R_{i 1}, R_{i 2} \mid x_{i 1}, x_{i 2}, \theta\right)=\left(\operatorname{Pr}\left[R_{i 1}^{*}<c_{1}\right]\right)^{I\left\{R_{i 1}=0\right\}}\left(\operatorname{Pr}\left[c_{1}<R_{i 1}^{*} \leq c_{2}, R_{i 2}^{*}<c_{2}\right]\right)^{I\left\{R_{i 1}=1, R_{i 2}=0\right\}} \\
& \quad\left(\operatorname{Pr}\left[c_{1}<R_{i 1}^{*} \leq c_{2}, R_{i 2}^{*} \geq c_{2}\right]\right)^{I\left\{R_{i 1}=1, R_{i 2}=1\right\}}\left(\operatorname{Pr}\left[R_{i 1}^{*} \geq c_{2}\right]\right)^{I\left\{R_{i 1}=2\right\}} .
\end{aligned}
$$

$\mathrm{I}\{$.$\} is an indicator function that is equal to one if the argument is true and zero$ otherwise.

Identification of the model, and in particular of $\rho$, requires all parameters to be the same for the first and second contact. The reason for making this assumption is that only the soft refusals are contacted a second time and not all individuals. A justification for this assumption is that, as discussed in Section 2, interviewers did not receive additional training in between the two cooperation attempts and soft refusals were not given additional incentives to cooperate the 
second time. A different threshold parameter for the second contact would not be separately identified (non-parametrically) from the correlation parameter. From a different perspective, the survey has no experimental implementation of the refusal conversion procedure; this prevents the identification of the effect of the refusal conversion procedure on unit response.

\section{EMPirical Results}

Table 3 reports the estimation results for three different empirical specifications of the unit response model outlined in Section 3. The models include individual, neighborhood, and interviewer characteristics as covariates. The individual characteristics are gender, age, type of accommodation, and city size. The neighborhood characteristics are population density and average individual income. These individual and neighborhood characteristics are time-constant covariates and do not change between the two cooperation attempts (at $t=1$ and $t=2$ ). As discussed above, most often a different interviewer is sent for the second cooperation attempt to convert the soft refusal (at $t=2$ ). Therefore the interviewer characteristics and month of contact are time-varying covariates. The interviewer characteristics are gender and age. In the final model I use interviewer specific effects, i.e. dummy variables for each interviewer are included in the model.

The estimates reported in Table 3 are of $\beta / \sigma_{u}$ and provide only insights in the direction and relative size of the effects of the covariates on the unit response probability. In order to quantify the associations, Table 4 reports the marginal effects of the covariates on the unit response probability. These marginal effects are based on the estimates of model 3 in Table 3. In all tables, significant estimates are in bold (at a 5 percent level of significance).

\subsection{Estimation Results}

The estimation results are presented in Table 3. The results of model 1 show that unit response is significantly lower among individuals aged 80 and over. There is no significant gender difference in unit response.

The results of model 2 show that the unit response rate among individuals living in houses is higher than the response rate among individuals living in apartments. Compared to individuals living in small cities, the unit response rate is relatively low among individuals living in large cities (with more than 200,000 inhabitants). Population density is not significantly associated with unit response. The month of interview plays a significant role; the response rate is lowest in September. ${ }^{4}$ The parabolic association between neighborhood income and unit response in model 2 implies a maximum response rate among individuals living in neighborhoods with an average income of 37,000 Guilders (about $€ 17,000$ ). The unit response rate among male interviewers is significantly lower than among female interviewers. The test statistics at the bottom of the table show that the association with age turns insignificant when using model 2 instead of model 1. Table 3 does not explicitly

${ }^{4}$ This is most likely a survey management issue. In September several scheduled interviews of respondents were mistakenly cancelled and these individuals were contacted again. This affected about 15 individuals. 
TABLE 3

Estimation Results ${ }^{\mathrm{a}}$

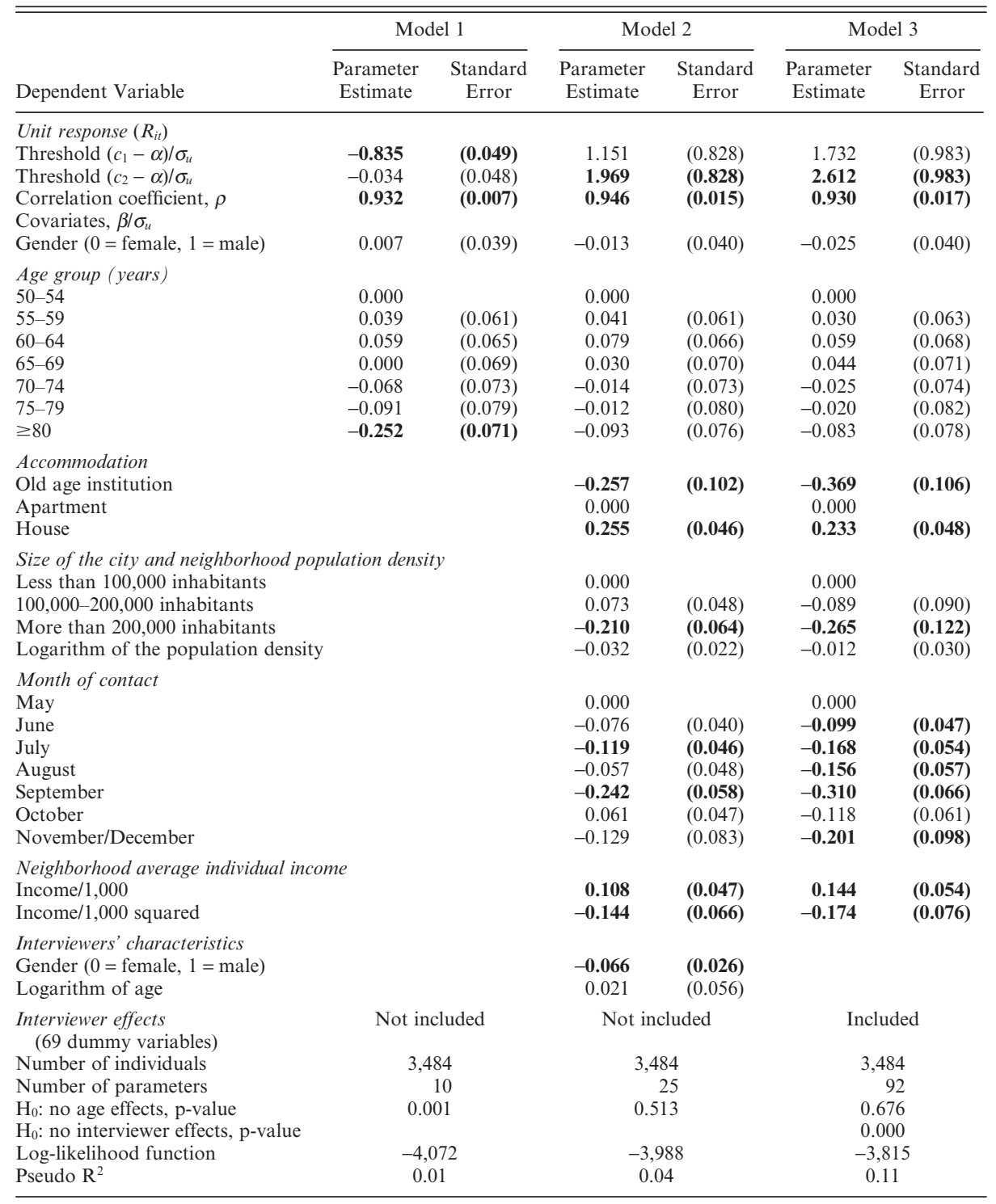

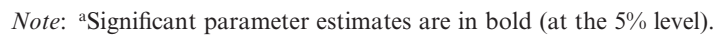

show it, but this age association turns insignificant because of controlling for whether or not the individual is living in an old age institution.

Model 3 controls for interviewer specific (fixed) effects. A consequence of this is that the covariates gender and age of the interviewer cannot be included in model 3. The influence of city size is, however, still identified because several interviewers were given addresses in two or three different sized cities. The test statistic at the 
bottom of the table, last column, shows that the interviewer specific effects are jointly significant. ${ }^{5}$ The most striking differences between the results of models 2 and 3 are the relatively larger negative estimated association with living in an old age institution and the change in the association with neighborhood income. Concerning the latter difference, the maximum response rate shifts from 37,000 Guilders in model 2 to 41,000 Guilders (about $€ 18,600$ ) in model 3. These changes in parameter estimates result from correlations between the observed covariates and the interviewer fixed effects and underline the importance of controlling for interviewer fixed effects.

I have experimented with interactions of income with the type of accommodation, size of the city, and whether or not an individual is aged 65 or over. None of these interaction effects turned out to be significant.

The estimated correlation coefficient $(\rho)$ is significant and equal to 0.93 . This implies that unit response at the second contact is strongly correlated with unit response at the first contact; this may be due to, for instance, unobserved individual specific characteristics.

\subsection{Marginal Effects}

Table 4 reports on the marginal effects on the unit response probability of changes in the covariates based on the estimation results of model 3 (Table 3). I obtain the marginal effects by comparing the probability of a baseline case with the probability of a case in which I change the value of only one of the covariates. The baseline case individuals have the following observed characteristics: female, 50-54 years old, contacted in May by an average performing interviewer (in terms of unit response rate), and living in an apartment in a city of less than 100,000 inhabitants and a neighborhood with median income and population density. Table 4 (top row) shows that the corresponding baseline response rate is equal to 58.8 percent. Below I compare the unit response probability of the reference individuals (the baseline) with the unit response probability of individuals with one different characteristic.

Compared to individuals who are living in an apartment, the unit response probability is 15 percent higher for individuals living in a house (8.8 percentage points). An implication of this result is that there is a unit non-response bias in the percentage of individuals living in a house based on the response sample. Individuals living in a city with more than 200,000 inhabitants have a 12 percent lower unit response rate than individuals living in a city with less than 100,000 inhabitants.

Relative to the baseline case, individuals living in an old age institution have a 25 percent lower unit response rate (14 percentage points). As individuals living in an old age institution such as nursing homes are more likely to be in bad health, this result could be explained by a negative correlation between unit non-response and health status as reported in Khare et al. (1994) and Cohen and Duffy (2002).

I assess the association between neighborhood average individual income and unit response for selected percentiles of the distribution of neighborhood average

${ }^{5}$ For 48 of the 69 , interviewer fixed effects are not significantly different from zero. 
income. Table 4 shows a strong positive association between unit response and neighborhood income. The positive correlation between neighborhood income and unit response is in line with the findings of Khare et al. (1994), Goyder et al. (2002), and Hudson et al. (2004). Under the assumption of positive correlations between housing value, homeownership, and income, these results are not in line with the finding in Kennickell (1999), who reports a negative correlation between housing value and unit response, but are in line with Dixon (2002), who reports that homeowners are more likely to respond compared to tenants in rented accommodation. The difference in unit response between the top and bottom deciles of the distribution of neighborhood income is about 12 percentage points. This amounts to about a 25 percent higher unit response probability among individuals in the top decile than among individuals in the bottom decile of the distribution of neighborhood average individual income.

TABLE 4

The Marginal Effects of the Observed Covariates on the Unit Response Probability ${ }^{\mathrm{a}}$

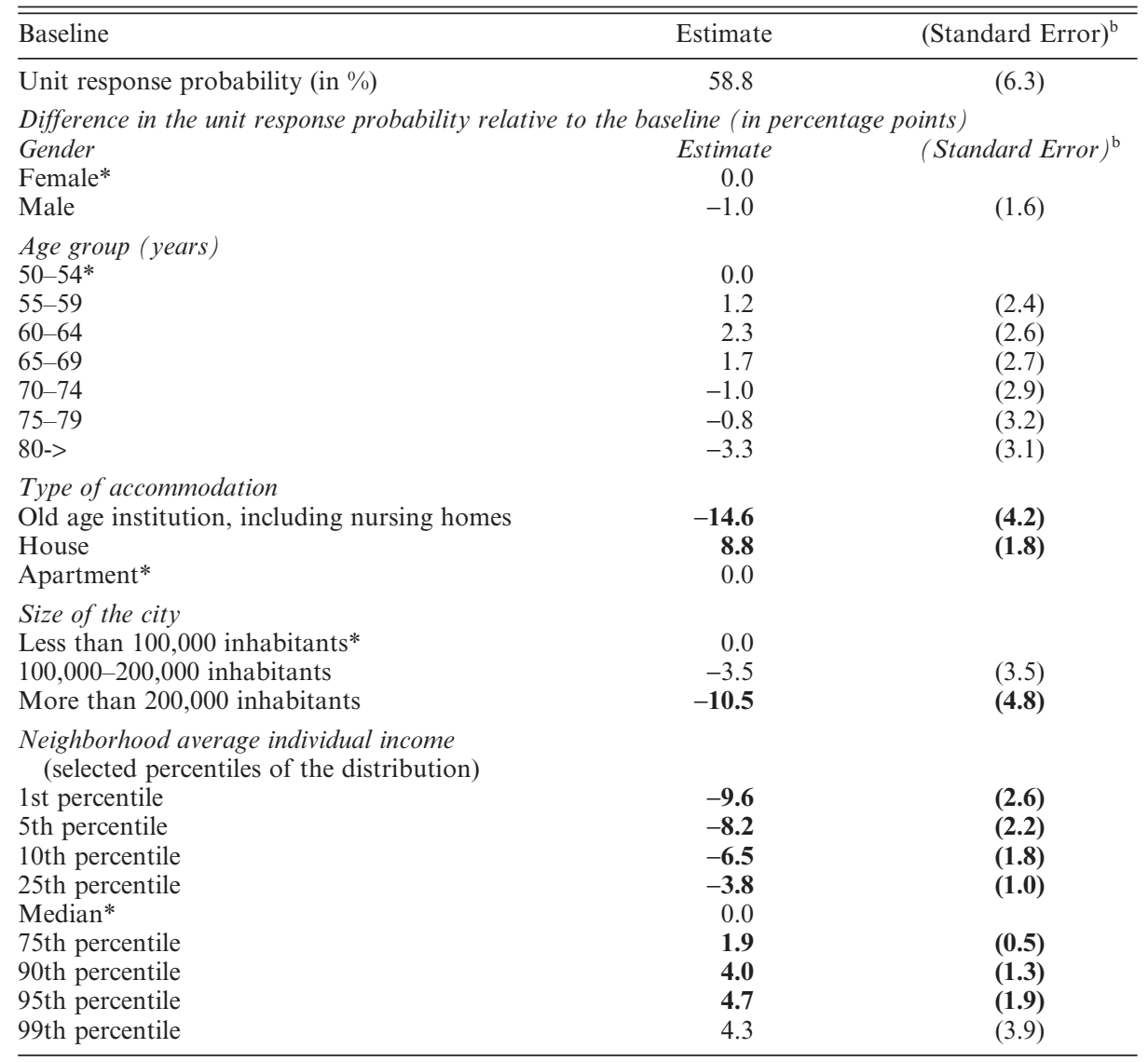

Notes: *Characteristics of the reference individual.

a $\partial \operatorname{Pr}\left[R_{i}^{*} \geq c_{2} \mid x_{i} ; \theta\right] / \partial x_{i}$; these effects are based on the estimates of model 3 (Table 3 ).

${ }^{\mathrm{b}}$ Significant estimates are in bold (at the $5 \%$ level). 


\section{Conclusions}

This paper has estimated the associations between individual and neighborhood characteristics and unit (non)-response in the 2004 Survey of Health, Ageing and Retirement in Europe (SHARE) in the Netherlands. This survey has a 44 percent unit non-response rate. The results have shown that, after controlling for age, gender, and interviewer effects, unit non-response is not random with respect to neighborhood average income, type of accommodation (a house or apartment), whether or not the individual lives in an elderly or nursing home, and size of the city. The association between neighborhood average income and unit nonresponse was of particular interest since income is a key variable in socioeconomic research. The results have shown that unit non-response is about 25 percent lower among individuals in the top than among individuals in the bottom of the distribution of neighborhood average income. This implies that the response sample is biased toward individuals living in the more wealthy neighborhoods.

\section{REFERENCES}

AAPOR (American Association for Public Opinion Research), Standard Definitions; Final Disposition of Case Code and Outcome Rate for Survey, AAPOR, Ann Arbor, MI, 2000.

Börsch-Supan, Axel, Agar Brugiavini, Hendrik Jürges, Johan Mackenbach, Guglielmo Siegrist, and Guglielmo Weber (eds), Health, Ageing and Retirement in Europe: First Results from the Survey of Health, Ageing and Retirement in Europe, Mannheim Research Institute for the Economics of Ageing, Mannheim, 2005.

Cohen, G. and John C. Duffy, "Are Nonrespondents to Health Surveys Less Healthy Than Respondents?" Journal of Official Statistics, 18(1), 13-23, 2002.

Copas, Andrew J. and Vern T. Farewell, "Dealing with Non-Ignorable Non-Response by Using an 'Enthusiasm-to-Respond' Variable," Journal of the Royal Statistical Society, Series A, 161, Part 3, 385-96, 1998.

De Heer, Wim, "International Response Trends: Results of an International Survey," Journal of Official Staistics, 15(2), 129-42, 1999.

De Leeuw, Edith D. and Wim De Heer, "Trends in Household Survey Nonresponse: A Longitudinal and International Comparison," in Robert M. Groves, Don A. Dillman, John L. Eltinge and Roderick J. A. Little (eds), Survey Nonresponse, Wiley Series in Probability and Statistics, John Wiley \& Sons, New York, 2002.

De Luca, Guiseppe and Oliver Lipps, "Fieldwork and Survey Management," in Axel Börsch-Supan and Hendrik Jürges (eds), Health Ageing and Retirement in Europe: Methodology, Mannheim Research Institute for the Economics of Aging, Mannheim, 2005.

De Luca, Guiseppe and Franco Peracchi, "Survey Participation in the First Wave of SHARE," in Axel Börsch-Supan and Hendrik Jürges (eds), Health Ageing and Retirement in Europe: Methodology, Mannheim Research Institute for the Economics of Aging, Mannheim, 2005.

Dixon, John, "Nonresponse Bias in the Consumer Expenditure Quarterly Survey," Proceedings of the American Statistical Association, Alexandria, VA, 2002.

Goyder, John, Keith Warriner, and Susan Miller, "Evaluating Socio-Economic Status (SES) Bias in Survey Nonresponse," Journal of Official Statistics, 18(1), 1-11, 2002.

Groves, Robert M. and Mick P. Couper, Nonresponse in Household Interview Surveys, Wiley Series in Probability and Statistics, John Wiley \& Sons, New York, 1998.

Groves, Robert M. and Kate A. McGonagle, "A Theory-Guided Interviewer Training Protocol Regarding Survey Participation,” Journal of Official Statistics, 17(2), 249-65, 2001.

Hudson, Darren, Lee-Hong Seah, Diane Hite, and Tim Haab, “Telephone Presurveys, Self-Selection, and Non-Response Bias to Mail and Internet Surveys in Economic Research," Applied Economics Letters, 11, 237-40, 2004.

Juster, F. Thomas and Richard Suzman, "An Overview of the Health and Retirement Study," Journal of Human Resources, Vol. 30, Special Issue on the Health and Retirement Study: Data Quality and Early Results, S7-56, 1995.

Kennickell, Arthur B., "Analysis of Nonresponse Effects in the 1995 Survey of Consumer Finances," Journal of Official Statistics, 15(2), 283-303, 1999. 
Khare, Meena, Leyla K. Mohadjer, Trena Ezzati-Rice, and Joseph Waksberg, "An Evaluation of Nonresponse Bias in NHANES III (1988-91)," in Proceedings of the Survey Research Methods Section, American Statistical Association, 949-54, 1994.

Korinek, Anton, Johan A. Mistiaen, and Martin Ravallion, "Survey Nonresponse and the Distribution of Income," Journal of Economic Inequality, 4, 33-55, 2006

Little, Roderick J. A. and Sonya Vartivarian, "On Weighting the Rates in Nonresponse Weights," Statistics in Medicine, 22, 1589-99, 2003.

Loosveldt, Geert, Michel Philippens, Ineke Stoop, and Jaak Billier, "Refusal Conversion Procedures in the European Social Survey," Documentation of the European Social Survey, http:/l www.europeansocialsurvey.org, 2004.

Marmot, Michael, James Banks, Richard Blundell, Carli Lessof, and James Nazroo (eds), Health, Wealth and Lifestyles of the Older Population in England: The 2002 English Longitudinal Study of Ageing, Institute for Fiscal Studies, London, 2003.

O'Muircheartaigh, Colm and Pamela Campanelli, "A Multilevel Exploration of the Role of Interviewers in Survey Non-Response," Journal of the Royal Statistical Society, Series A, 162, Part 3, 437-46,1999.

Pickery, Jan and Geert Loosveldt, "A Multilevel Multinomial Analysis of Interviewer Effects on Various Components of Unit Nonresponse,” Quality and Quantity, 36, 427-37, 2002.

Snijkers, Ger, Joop Hox, and Edith D. de Leeuw, "Interviewers' Tactics for Fighting Survey Nonresponse," Journal of Official Statistics, 15(2), 185-98, 1999.

Statistics Netherlands, Kerncijfers Wijken en Buurten 1999, Voorburg/Heerlen, 2000.

Stoop, Ineke, The Hunt for the Last Respondent: Nonresponse in Sample Surveys, Social and Cultural Planning Office of the Netherlands, The Hague, 2005. 